\title{
Serum Carnosinase Deficiency Concomitant with Mental Retardation
}

\author{
William H. Murphey ${ }^{[18]}$, Donald G. Lindmark, Linda I. Patchen, Mary E. Housler, Emma K. Harrod, \\ and Luis Mosovich \\ Department of Pediatrics, School of Medicine, The State University of New York at Buffalo \\ and the Children's Hospital of Buffalo, Buffalo, New York, USA
}

\begin{abstract}
Extract
A family was studied in which two boys with progressive neurologic disease exhibited carnosinemia (20-30 $\mu \mathrm{mol} / \mathrm{ml}$ serum), carnosinuria $(60-200 \mu \mathrm{mol} / 24 \mathrm{hr}$ ), and a deficiency in serum carnosinase activity $(<0.03 \mu \mathrm{mol} / \mathrm{hr} / \mathrm{ml})$. Their sister, who is apparently both physically and mentally normal, also exhibits carnosinuria and is deficient in serum carnosinase activity.

Tissue extracts of liver, kidney, and spleen obtained at autopsy of one of the male patients were assayed for carnosinase and other enzyme activities and were subjected to starch block electrophoresis at pH 7.0 for $4 \mathrm{hr}$ at $4^{\circ}$. The starch block electrophoreses, under conditions which readily demonstrate two electrophoretic forms of the enzyme in normal tissue extracts, revealed that only one of the two forms was present. This activity corresponded to the slower form in normal tissues and appeared to be present in normal concentrations.
\end{abstract}

\section{Speculation}

The excretion of abnormal quantities of carnosine and/or anserine in the urine appears to be related to inherited serum carnosinase deficiency, but further studies are required to determine the association of the deficiency of the enzyme with progressive neurologic disease as well as the nature and role of the two electrophoretic forms of tissue carnosinase activity.

\section{Introduction}

Carnosine and anserine are dipeptides composed of $\beta$-alanine and either L-histidine or I-methylhistidine, respectively. Each is hydrolyzed to its constituent amino acids by the enzyme, carnosinase (EC. 3.4.3.3) [5]. It is generally accepted that the diet is a major source of carnosine and is, perhaps, the sole source of anserine for humans. Anserine, if present, disappears from the urine of normal individuals when they are placed on meat-free diets while l-methylhistidine concentrations are reduced significantly $[2,3]$.
Perry et al. described two patients with progressive neurologic disease characterized by convulsions, severe retardation, deafness, and blindness associated with carnosinemia, carnosinuria, anserinuria, and a deficiency in serum carnosinase activity. Neither patient excreted 1-methylhistidine when placed on chicken diets containing large amounts of anserine [7, 8]. Another patient with progressive neurologic disease, convulsions, and severe retardation associated with carnosinuria and a deficiency in serum carnosinase activity was described by Van Heeswijk et al. [13]; carnosin- 
emia was not observed at any time and significant quantities of 1-methylhistidine were detected in the urine while the patient was on a regular diet. Others have reported carnosinuria or imidazole-uria among patients with cerebromacular degeneration; however, serum carnosinase levels were not studied $[1,12]$.

\section{Patients, Materials and Methods}

\section{Patient 1 (CH340-173; Birth Date October 6, 1961)}

This patient was a Caucasian male who was considered normal until he developed generalized seizures and intermittent twitching on the right arm and face. There was slow, progressive neurologic deterioration and by 6 months of age he was lethargic, had slight strabismus, hyperactive deep tendon reflexes, and moderate spasticity of the extremities. Physical growth continued at a normal rate for 2 years but by $65 \%$ years of age he was a small, nonresponsive boy who had generalized muscle wasting and flexion deformities of his knees and elbows. He did not respond to visual or auditory stimuli and had frequent seizures, hyperactive tendon reflexes, absent abdominal reflexes, bilateral Babinski reflexes, normal optic fundi, no rashes, and no organomegaly. At this time his electroencephalogram showed diffuse seizure discharges and a slow wave dysrhythmia, more marked on the left. Complete blood count, urinalysis, serum calcium, phosphorous, alkaline phosphatase, fasting blood sugar, blood-ureanitrogen, spinal fluid, and cytogenetic studies were all normal. He had many episodes of respiratory infection and died at the age of $71 / 2$ years after surgery for an apparent intestinal obstruction concomitant with a respiratory infection. A postmortem examination revealed atelectasis with pneumonia. The histopathology of the nervous system has been reported elsewhere [11].

\section{Patient 2 (CH376-100; Birth Date January 6, 1964)}

This patient is the sister of patient 1. She is developing normally, has normal intelligence, and no apparent physical abnormalities.

\section{Patient 3 (CH410-350; Birth Date October 7, 1965)}

Patient 3 is the brother of patients 1 and 2. He was first noted to be abnormal at 4 weeks of age when slight seizures began. At that time he was found to be an alert, well developed infant who had good head control, responded normally to light and sound, but had brisk tendon reflexes. Physical growth continued but neurologic maturation ceased and there was gradual deterioration. At 23/4 years of age he weighed 12.0 $\mathrm{kg}$, was well developed, and moved all extremities. $\mathrm{He}$ had generalized increased muscle tone, hyperactive reflexes and held his elbows, wrists and feet in flexion. He was irritable and poorly responsive, but did react to loud noises, bright lights, and pinpricks. He had normal optic fundi, no organomegaly, and laboratory studies including a complete blood count, urinalysis, serum chemistries, spinal fluid studies, blood-urea-nitrogen test, serum glutamate oxalate transaminase, and cytogenetic analysis were all normal. An electroencephalogram showed diffuse seizure discharges and slow wave dysrhythmia.

\section{Family History}

The father is an intelligent, healthy Caucasian born in New York State. His family ancestry is unknown. The mother is an intelligent, healthy woman of English and Italian ancestry who was born in Great Britain. Consanguinity is unlikely. The mother had two spontaneous, first trimester abortions before the birth of patient 1; hex pregnancies with patients 2 and 3 were carefully monitored while she was enrolled in the Child Development Project under the auspices of the National Institutes of Health. She had no brothers and sisters and her father's relatives are not known to her. The maternal grandmother had four brothers and five sisters who in turn have had 29 children, all in good health.

\section{Specimens}

Sera and urine specimens were stored frozen with no preservatives added. Tissues obtained at autopsy (within $18 \mathrm{hr}$ of death) were immediately homogenized in $250 \mathrm{~mm}$ sucrose and centrifuged at 2,000 $\times g$ for 20 min; the supernatant liquids were stored frozen.

\section{Paper and Column Chromatography}

Aliquots of urine containing $10 \mathrm{mg}$ creatine were applied to Whatman no. 3MM filter paper for two-dimensional chromatography with the following solvents: (1st dimension) pyridine/acetone/ammonia/water $(45 / 30 / 10 / 15)$, and (2nd dimension) isopropanol/ formic acid/water (75/12.5/12.5) [9]. Amino acids were detected by spraying with $0.25 \%$ ninhydrin in acetone. Pauly's reagent was applied separately or after the ninhydrin spray. Aliquots of desalted urine containing 0.5 $\mathrm{mg}$ creatinine and deproteinized serum specimens were assayed quantitatively by means of a Beckman/Spinco model 120B amino acid analyzer [14]. 


\section{Carnosinase Assay}

All reagents and sera were prepared or diluted in 0.3 $\mathrm{M}$ Tris-HCl [15] buffer, $\mathrm{pH}$ 8.0. Carnosinase assays were performed as previously described [6] with the fluorometric assay of free histidine described by Shore et al. [10]. Where required, corrections were made for contaminating histidinase activity.

\section{Starch Block Electrophoresis}

Electrophoreses were performed at $4^{\circ}$ using hydrolyzed potato starch [16] in potassium phosphate-citric acid buffer, $\mathrm{pH} 7.0$, with a constant voltage of $180 \mathrm{~V}$ $(7.5 \mathrm{ma} / \mathrm{cm})$ applied for $4 \mathrm{hr}$ [4]. Consecutive sections $(1 \mathrm{~cm})$ of the starch block were suspended either directly in $1.8 \mathrm{ml}$ carnosinase assay mixture or in 2.0 of $0.3 \mathrm{M}$ Tris- $\mathrm{HCl}, \mathrm{pH} 8.0$, to elute enzymes and proteins for other assays.

\section{Results}

The appearance of progressive neurologic disease and similarities in clinical symptoms in two male siblings suggested the possibility of an inherited metabolic deficiency and prompted amino acid analyses of blood and urine specimens. Chromatography of 24-hr urine specimens obtained from all members of the family while they were on regular, but undefined diets revealed excretions of abnormal amounts of carnosine by the two mentally retarded boys $(63$ and $204 \mu \mathrm{mol} / 24$ hr) and their apparently normal sister $(314 \mu \mathrm{mol} / 24$ hr). There was nothing remarkable about the urine specimens from the parents. Histidine and I-methylhistidine were present in all specimens examined.

The two boys were admitted separately to the Clinical Research Center at Children's Hospital for further study. Each child was maintained on a regular hospital diet for the first 3 days and then on a meat-free (low carnosine) diet during days 4, 5, 6, and 7. An oral carnosine load $(200 \mathrm{mg} / \mathrm{kg})$ was administered on the morning of day 7 . On days 8,9 , and 10 each child received chicken 3 times a day to provide a diet which was high in anserine. The results obtained with $p a$ tient $l$ are presented in Figure 1 ; they establish that the carnosinuria was not due simply to an abnormally high intake of carnosine. When anserine was introduced into the diet, 1-methylhistidine was excreted into the urine in significant quantities. The temporal sequence of rise and fall of carnosine and histidine levels in blood and of anserine and 1-methylhistidine in urine during carnosine-loading and high anserine diet, respectively, suggested that these boys were not
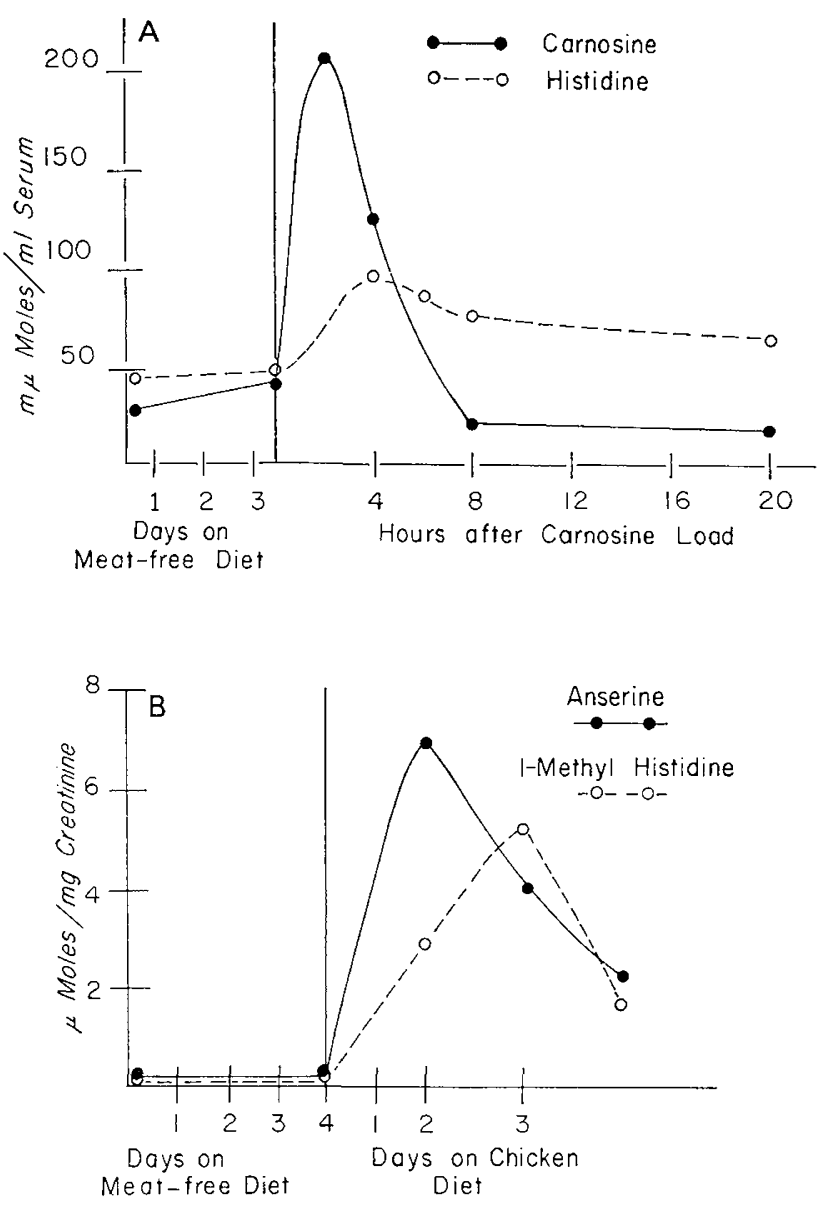

Fig. 1. Amino acid concentrations in $(A)$ blood and $(B)$ urine specimens from patient 1 while on controlled diets and during a carnosine load test (day 3).

totally lacking in carnosinase activity. However, when carnosinase activity in their sera was assayed as described by Perry et al. [7], none was detectable. Subsequent assays using prolonged incubation and a more sensitive, fluorometric assay for free histidine did reveal very low levels $(<0.03 \mu \mathrm{mol} / \mathrm{hr} / \mathrm{ml})$ of carnosinehydrolyzing activity in their sera.

Sera from 57 normal adults, children, and newborn infants were assayed for carnosinase activity by means of the fluorometric assay to determine the distribution of this enzyme activity in a normal population. The results of this survey are presented in Figure 2. There is no correlation between the levels of serum carnosinase activity and the sex of the donor; but there is a correlation $(r=0.67)$ with the donor's age. Carnosinase activity was not detectable in the sera of five newborn infants (cord blood) nor was it detectable in two of four children at 2 years of age. Increasing levels 


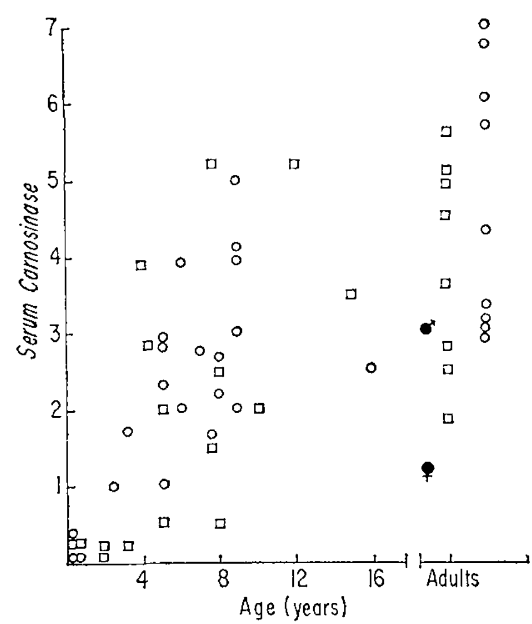

Fig. 2. Distribution of carnosinase activitics in sera from normal children and adults. Carnosinase activity is plotted as histidine liberated, micromoles per hour per milliliter of serum. The father and mother of the carnosinase-deficient children are indicated by the $\delta$ and $o$, respectively; other males and females are indicated by $\square$ and $\bigcirc$, respectively.

of activity, but with wide variations, were found in older children. The levels of activity seen in adults $(2-7 \mu \mathrm{mol} / \mathrm{hr} / \mathrm{ml})$ were attained as early as 3 years of age by some children; however, the calculated line of regression for these data indicates that the majority of children do not reach the adult range of serum enzyme activities until they are at least 10 years of age.

Carnosinase assays of sera from the parents of the patients are also shown in Figure 2. The activity in the mother's serum was the lowest value observed among the adults tested. The activity in the sera from each of the three children was less than $1 \%$ of the mean of normal adult levels and was well below that expected for each child's age group. Various mixtures of these sera with a normal serum yielded, within experimental error, the levels of carnosinase activity expected by simple dilution, which indicated that the deficiency in activity observed in the children's sera is not due to a circulating inhibitor of the enzyme. The carnosinase activity in normal sera and in sera from both parents of the patients showed only quantitative differences; that is, no differences were detected when equal amounts of carnosinase-hydrolyzing activity were tested on such peptides as anserine, alanylhistidine, glycylhistidine, homocarnosine, and histidylglycine [6].

\section{Electrophoretic Studies}

Tissue extracts of liver, kidney, and spleen obtained at autopsy of patient 1 were assayed for carnosinase and other enzyme activities and were subjected to starch block electrophoresis at $\mathrm{pH} 7.0$ for $4 \mathrm{hr}$ at $4^{\circ}$. Although the specific activity of the patient's carnosinase was approximately normal in the kidney extracts, it was slightly less than normal in the spleen and much lower than normal in the liver (Table I). No carnosinase activity was detectable in muscle tissue from either the patient or normal adults. Lactic and malic dehydrogenase activities were within normal limits in all specimens.

The starch block electrophoreses, under conditions which readily demonstrate two electrophoretic forms of the enzyme in normal tissue extracts [6], revealed that only one of the two forms was present in extracts of the patient's tissues. This activity corresponded to the slower form in normal tissues and appeared to be present in normal concentrations. These enzyme profiles are presented in Figure 3.

\section{Discussion}

Previously, only three patients have been reported in whom the carnosinase activity in serum was studied

Table $I$. Carnosinase assays of autopsy specimens ${ }^{1}$

\begin{tabular}{llll}
\hline \multirow{2}{*}{ Source } & \multicolumn{3}{c}{ Histidine, $\mu \mathrm{mol} / \mathrm{hr} / \mathrm{mg}$ protein } \\
\cline { 2 - 4 } & Liver & Kidney & Spleen \\
\hline Adult male & 0.24 & 0.55 & 0.37 \\
Adult female & 0.12 & $0.57^{1}$ & 0.73 \\
Patient 1 & 0.03 & $0.64^{2}$ & \multirow{2}{*}{0.48} \\
\hline
\end{tabular}

1 Cortex only.

${ }^{2}$ Medulla only.

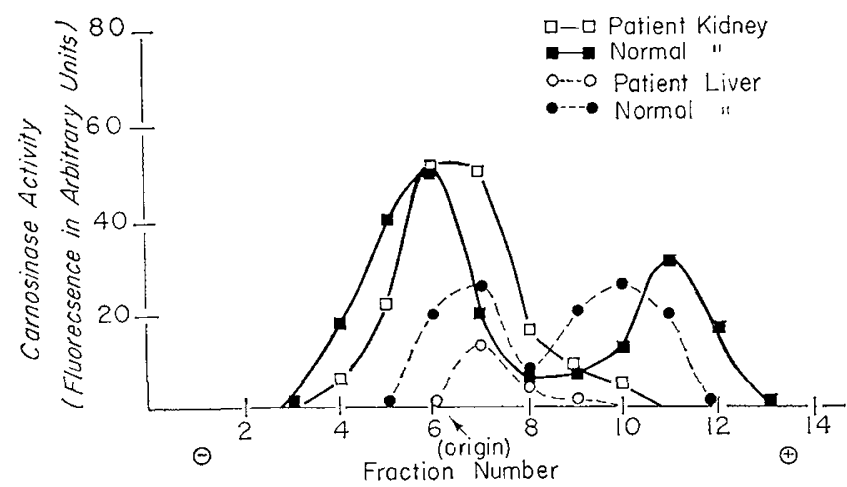

Fig. 3. Profile of carnosinase activity in tissue extracts from a normal adult and from palient 1 after starch block electrophoresis at $\mathrm{pH}$ 7.0. Sections (approximately $1 \mathrm{~cm}$ ) of the starch blocks were eluted and assayed fluorometrically; carnosinase activity is plotted in arbitrary units. The liver extracts $(O, \bullet)$ and the kidney extracts $(\square, \mathbf{\square})$ were run on separate starch blocks and are, therefore, not directly comparable. 
relative to observations of carnosinuria and carnosinemia. Two patients described by Perry et al. [8] were deficient in serum carnosinase activity $(<0.05 \mu \mathrm{mol} /$ $\mathrm{hr} / \mathrm{mI}$ ) and did not excrete 1-methylhistidine in their urine, even when placed on diets containing large quantities of anserine. The single patient described by Van Heeswijk et al. [13] was also deficient in serum carnosinase activity $(0.07 \mu \mathrm{mol} / \mathrm{hr} / \mathrm{ml})$ and did exhibit carnosinuria; but unlike Perry's patients, the child did not exhibit carnosinemia and did excrete l-methylhistidine into his urine. In these respects, the two boys we have studied resembled Van Heeswijk's patient in that they are deficient in serum carnosinase activity $(<0.03$ $\mu \mathrm{mol} / \mathrm{hr} / \mathrm{ml}$ ) and do excrete 1-methylhistidine into their urine; however, unlike Van Heeswijk's patient, carnosinemia was observed in patient 1 while he was on a regular diet and anserinemia was observed in both children while they were on diets of chicken. These differences in carnosinemia are reflected in the renal clearances calculated for carnosine for Perry's patient $(23 \mathrm{ml} / \mathrm{min})$, for Van Heeswijk's patient $(>300$ $\mathrm{ml} / \mathrm{min}$ ) and our patients (patient $1=10 \mathrm{ml} / \mathrm{min}$; patient $3=87 \mathrm{ml} / \mathrm{min}$ ) while on regular diets.

Perry reported three other, unrelated children with mental retardation, and Bessman and Baldwin [1] reported five patients in three unrelated families who excreted carnosine and 1-methylhistidine into their urine. Serum carnosinase activities were not reported, but Bessman's studies with histidine ${ }^{-14} \mathrm{C}$ suggested that his patients had decreased renal clearances or increased synthesis of histidine-containing dipeptides [12].

Even though our two patients were deficient in serum carnosinase activity, indirect evidence that they had some capacity to metabolize carnosine and anserine was provided by the temporal rise and fall of histidine in the blood upon challange with carnosine and by the increased excretion of I-methylhistidine upon introduction of anserine into their diet. Direct evidence for this capacity was obtained by assays of tissues obtained at autopsy of patient 1 . The results were like those obtained by Perry, who observed significant levels of carnosinase activity in liver, kidney, and heart tissues obtained from autopsy of one of his patients.

We have previously reported the existence of two electrophoretic forms of carnosine-hydrolyzing activity in normal liver, kidney, spleen, and heart tissues; no differences were detected between these two forms in substrate specificity or in relative rates of activity on various dipeptides [6]. Inasmuch as the tissues of our patient were deficient in only one of the two forms, it would suggest that the two forms of the enzyme are under separate genetic control. These two forms of the enzyme provide a possible explanation for the observations made by us and by Perry on tissues obtained at autopsy; however, it would be interesting to learn whether Perry's patients, who were apparently incapable of hydrolyzing anserine, had the deficiency in one or both forms of the enzyme.

The three mentally retarded, carnosinase-deficient patients reported by Perry et al. [8] and by Van Heeswijk et al. [13] were males, as are the two mentally retarded children in this family. On the other hand, the carnosinase-deficient sister is both physically and mentally normal. Although these observations raise the possibility of an X-linked trait, it seems unlikely, inasmuch as the pedigree of this family includes four maternal great uncles and several male $2^{\circ}$ and $3^{\circ}$ cousins born to maternal gxeat aunts, and all of these relatives are normal.

The sister of these two mentally retarded boys is of particular interest because she is also deficient in serum carnosinase activity and exhibits carnosinuria. She could have the same genetic endowment as her brothers in regard to the determinants of carnosinase activity. If so, it would suggest that the retardation of her brothers is not causally related to the enzyme deficiency. Alternatively, the low level of activity in her serum at this time may be a reflection of the age-dependent association of serum levels observed among normal children superimposed upon a heterozygous genotype. We hope that this child can be followed into adolescence to establish her capacity to metabolize carnosine and anserine as related to her "adult" levels of serum carnosinase.

Little is yet known of the role of this enzyme and its substrate in the normal development and physiology of man or animals. As with other inborn errors of metabolism which have been identified in patients coming to attention due to physical or mental retardation, further studies are required to determine the incidence of carnosinase deficiency in both normal and abnormal populations and to establish what relation, if any, exist between the enzyme deficiency, the excretion of histidine metabolites, and the appearance of neurologic disease.

\section{References and Notes}

1. Bessman, S. P., ANd Baldwin, R.: Imidazole aminoaciduria in cerebromacular degeneration. Science, 135: 789 (1962).

2. Crush, K. G.: Carnosine and related substances in animal tissues. Compr. Biochem. Physiol., 34: 3 (1970). 
3. Datra, S. P., AND HARRIS, H.: Dietary origin of urinary methyl-histidine. Nature, 168: 296 (1951).

4. Fine, I. H., ANd Costello, I. A.: The use of starch electrophoresis in dehydrogenase studies. Methods Enzymol., 6: 958 (1963).

5. Hanson, H. T., and Smith, E. L.: Carnosinase: An enzyme of swine kidney. J. Biol. Chcm., 179: 789 (1949).

6. Murphey, W. H., Patchen, L. I., and Lindmark, D. G.: Carnosinase: A fluorometric assay and demonstration of two electrophoretic forms in human tissue extracts. Clin. Chim. Acta, 42: 309 (1972).

7. Perry, T. L., Hansen, S., And Love, D. L.: Serum-carnosinase deficiency in carnosinemia. Lancet, June 8, 1229 (1968).

8. Perry, T. L., Hansen, S., Tischler, B., Bunting, R., and BERRY, K.: Carnosinemia, A new metabolic disorder associated with neurologic disease and mental defect. New Engl. J. Med., 227: 1219 (1967).

9. Shaw, K. N. F., Personal communication.

10. Shore, P. A., Burkhalter, A., ANd Cohn, V. H.: A method for the fluorometric assay of histamine in tissues. J. Pharmacol. Exp. Ther. 127: 182 (1959).

11. Terrlan, K. L., And Cares, H. L.: Histopathology of the nervous system in carnosinase enzyme deficiency with mental retardation. Neurology, 22: 644 (1972).

12. Tocci, P. M., and Bessman, S. P.: Histidine peptiduria. In: W. L. Nyhan: Amino Acid Metabolism and Genetic Variation, (McGraw-Hill, New York, 1967).

13. Van Heeswijk, P. J., Trijbels, J. M. F., Schretlen, E. D. A. M., Van Munster, P. J. J., and Monnens, L. A. H.: A patient with a deficiency of serum-carnosinase activity. Acta Paediat. Scand., 58: 592 (1969).

14. Beckman/Spinco, Palo Alto, Calif.

15. Sigma Chemical Company, St. Louis, Mo.

16. Connaught Medical Research Laboratories, Toronto, Ontario, Canada.

17. This investigation was supported in part by Grant no. RR628, General Clinical Research Centers Program of the Research Resources, Grant no. PH 43-68-6, Children's Hospital of Buffalo Child Development Study, Grant no. HD-03967, National Institutes of Health, and Project no. 435, Maternal and Child Health Services.

18. Requests for reprints should be addressed to: DR: WILlxaM H. Murphex, Ph.D., Children's Hospital, 219 Bryant Street, Buffalo, N. Y. 14222 (USA).

19. Accepted for publication February 5, 1973. 